\title{
Genetic Parameter Estimates for Growth Traits from Diallel Tests of Loblolly Pine Throughout the Southeastern United States
}

\author{
By S. E. McKeand ${ }^{1),{ }^{*} \text {, B. } \text { LI }^{1)} \text {, J. E. GRISSOM }}{ }^{1)}$, F. IsIK ${ }^{1)}$ and K. J. S. JAYAWICKRAMA ${ }^{2)}$
}

(Received $11^{\text {th }}$ October 2006)

\begin{abstract}
Variation in heritability and in genetic correlation estimates were evaluated for juvenile tree height and volume for six testing areas of loblolly pine (Pinus taeda L.) in the southeastern United States. Variance components and their functions (heritability and type B genetic correlations) were estimated from 265 six-parent disconnected diallel series, tested in almost 1000 trials (4 tests per diallel series). Original data were collected at age 6 years from about one million trees (265 diallel series x 30 crosses x 36 trees per cross/site x 4 sites) planted in field tests. Genetic tests were from the second cycle of breeding in the North Carolina State University - Industry Cooperative Tree Improvement Program. The overall unbiased individual-tree narrow-sense heritability for height was 0.19 and for volume was 0.16 . The broad-sense heritabilities for height (0.24) and for volume $(0.22)$ were higher than narrow-sense heritabilities due to the presence of non-additive genetic variance. There were moderate regional differences in these estimates, with tests in the Lower Gulf Coastal Plain tending to have the highest heritabilities for growth traits. There was very little association between site index and heritability, but heritabilities were higher on sites with the highest survival and highest test precision. Genotype $\mathrm{x}$ environment interactions were generally low both for half-sib and full-sib families, indicating that families can be operationally deployed to different sites with little concern about unpredictable performance.
\end{abstract}

Key words: Genetic correlation, genetic gain, genotype x environment interaction, heritability, Pinus taeda L.

\section{Introduction}

Loblolly pine (Pinus taeda L.) is the most widely planted forest tree species in the United States and is the most economically important species for landowners and the forest products industry in the South. Almost one billion seedlings are planted each year, virtually every one the result of aggressive tree improvement programs (McKeAnd et al., 2003b). Cooperators in the North Carolina State University - Industry Cooperative Tree Improvement Program (NCSU-ICTIP) started breeding and testing over 3000 plantation selections and over 700 second-generation selections in the early

\footnotetext{
1) Cooperative Tree Improvement Program, Department of Forestry and Environmental Resources, Box 8002, North Carolina State University, Raleigh, NC, 27695-8002, USA.

2) Northwest Tree Improvement Cooperative, Department of Forest Science, 321 Richardson Hall, Oregon State University Corvallis, OR 97331-5752, USA.

*) Corresponding author: Steven E. McKeand, Cooperative Tree Improvement Program, Department of Forestry and Environmental Resources, Box 8002, NC State University, Raleigh, NC 27695-8002, USA. Phone: +1-919-515-6073, Fax +1-919-5153169, E-mail: Steve_McKeand@ncsu.edu.
}

1980's. The second cycle of breeding and testing has been completed, and progeny test measurements are now available for over 3000 parent trees.

This enormous data set that includes genetic and environmental components of variation is extremely useful for tree breeders to optimize selection strategies in loblolly pine programs as well as to fine-tune breeding strategies. Program-wide summaries of genetic parameters have been published for several conifer species (e.g. Dieters et al., 1995; Hodge and DvoraK, 1999; HodGe and WhITE, 1992; JAYAWICKRAMA, 2001; ISIK et al., 2005). A similar published summary for loblolly pine would be appropriate and useful; results of firstgeneration loblolly pine tests have been previously reported (Li et al., 1996).

As tree breeding progresses into advanced-generations, breeders are challenged to keep obtaining gain quickly and in a cost-effective manner. High individualtree heritability is obviously important, since predicted gains are proportional to heritability. There are a few reports on the effects of silvicultural treatments such as mechanical site preparation and weed control on heritability (e.g. HUBER et al., 2003; LOPEZ-UPTON et al., 1999; WooDs et al., 1995), but tree breeders still have more to learn about what makes an ideal progeny test site. It would be interesting to study whether two different types of test site (cutover ex-forest sites vs. stumpfree agricultural land) used in the NCSU-ICTIP secondcycle tests resulted in noticeably different outcomes.

In this paper, we report the results from age 6-year measurements of growth traits for over one million trees planted in almost 1000 individual trials (265 diallel series each with 3 or 4 sites/per series). The scope of the second-cycle testing effort with control-pollinated families is unparalleled in tree improvement programs, and the results have wide ranging implications for loblolly pine breeding and for other tree breeding programs around the world.

\section{Materials and Methods \\ Experimental materials and data description}

Parent trees for the second cycle of breeding in the Cooperative originated from two sources; plantation selections and second-generation selections. More than 700 second-generation trees that were selected from crosses among superior first-generation parents were included in the breeding program. Most trees (3120 out of total 3800 selections) were phenotypic selections from plantations established in the 1940's to the 1960's that did not originate from tree improvement programs. Thus, these plantation selections were presumably 
unrelated to trees in the second-generation population (see WEIR and ZoBEL, 1975 for details about the origin of trees). Selections were bred in six-parent disconnected half-diallels, resulting in a total of 15 full-sib families per diallel; no selfs or reciprocal crosses were made (TALBERT, 1979). The resulting progeny were planted in balanced test series (the goal was four tests per test series), each comprised of progeny from two or occasionally three diallels. At each of the four test locations, a randomized complete block design with six blocks was used, and each full-sib family was planted in 6-tree plots in each block. A total of 265 pairs of six-parent half-diallels (series) were field-tested in 977 progeny trials throughout the southeastern USA.

At age six years, height, diameter at breast height (DBH), presence or absence of fusiform rust galls (caused by Cronartium quercuum (Berk) Miyabe ex Shirai f. sp. fusiforme), stem straightness, and survival were assessed for each tree. Volume per tree was estimated using the formula of GOEBEL and WARNER (1966). Age six years is the standard selection age for loblolly pine in the NCSU-ICTIP Program (McKEAND, 1988; LI et al., 1996; XIANG et al., 2003a), and only growth traits (height and volume) at age six are presented in this paper.

A linear mixed model was fitted to data within a test series to estimate variance components (XIANG and LI, 2001).

$$
\begin{array}{r}
Y_{i j o k l m}=\mu+T_{i}+B_{j(i)}+D_{o}+G_{k(o)}+G_{l(o)}+S_{k l(o)}+ \\
T G_{i k(o)}+T G_{i l(o)}+T S_{i k l(o)}+P_{i j o k l}+E_{i j o k l m}
\end{array}
$$

Where $Y_{i j o k l m}$ is the $m$ th observation of the $j$ th block within $i$ th test (location) for the $k l$ th cross within oth diallel; $\mu$ is the overall mean; $T_{i}$ is the $i$ th fixed test environment effect, $i=1$ to $t ; B_{j(i)}$ is the fixed effect of $j$ th block within $i$ th test, $j=1$ to $b ; D_{o}$ is the oth fixed diallel effect, $o=1$ to $d ; G_{k(o)}$ or $G_{l(o)}$ is the random general combining ability (GCA) effect of the $k$ th female or $l$ th male parent within oth diallel, $k, l=1$ to $p, k<l, k \neq l \sim \mathrm{NID}$ $\mathrm{N}\left(0, \sigma_{g}^{2}\right) ; S_{k l(o)}$ is the random specific combining ability (SCA) effect of $k$ th and $l$ th parents within oth diallel $\sim \mathrm{NID} \mathrm{N}\left(0, \sigma_{s}^{2}\right) ; T G_{i k(o)}$ or $T G_{i l(o)}$ is the random effect of $i$ th test by GCA effect of $k$ th female or $l$ th male parent within oth diallel $\sim \mathrm{NID} \mathrm{N}\left(0, \sigma^{2}{ }_{g t}\right) ; T S_{i k l(o)}$ is the random effect of $i$ th test by SCA effect of $k$ th female and $l$ th male parents within oth diallel $\sim \mathrm{NID} \mathrm{N}\left(0, \sigma^{2}{ }_{s t}\right) ; P_{i j o k l}$ is the random plot effect for the $k l$ th cross within oth diallel in the $j$ th block within $i$ th test $\sim \mathrm{NID} \mathrm{N}\left(0,\left(\sigma_{p}^{2}\right) ; E_{i j o k l m}\right.$ is the random within plot error term $\sim$ NID $N\left(0, \sigma^{2}{ }_{e}\right)$. All random effects are assumed to be independent of each other. The model was analyzed by using a SAS code developed for diallels (XIANG and LI, 2001).

Additive $\left(\sigma_{\mathrm{A}}^{2}=4 \sigma_{\mathrm{g}}^{2}\right)$ and non-additive $\left(\sigma_{\mathrm{NA}}^{2}=4 \sigma_{\mathrm{s}}^{2}\right)$ genetic variances were derived from observed variances and their causal relationships with variance of GCA and SCA effects (XIANG et al., 2003b). Individual-tree narrow-sense heritability $\left(h^{2}{ }_{N S}\right)$ for each diallel set was estimated as the ratio of additive genetic variance to

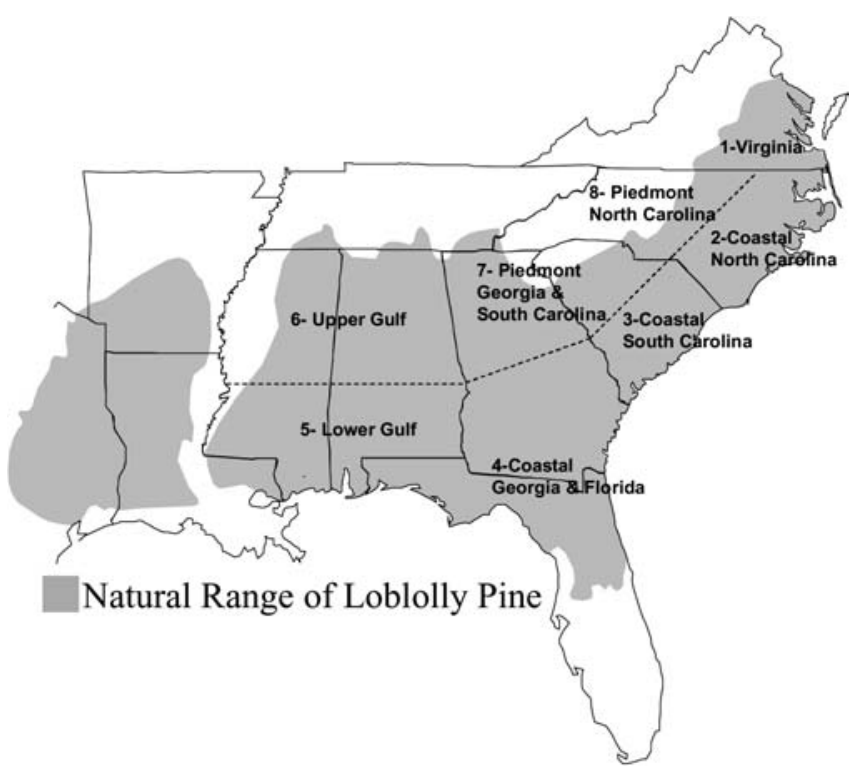

Figure 1. - Natural range of loblolly pine showing the general locations of the Test Areas used in the second cycle of testing in the NC State Tree Improvement Cooperative. For these analyses, tests in the northern half of Areas 2 and 8 were combined with Area 1, and tests in the southern half of Areas 2 and 8 were combined with Areas 3 and 7, respectively.

Table 1. - The means ( \pm one standard error of the mean) for tree height, volume, survival and coefficients of variation of plot-to-plot variance (\%) at age 6 years in different geographic regions in the NCSU-ICTIP, diallel test series.

\begin{tabular}{lccccc}
\hline NCSU Test Area & \#Series & Height $(\mathrm{m})$ & Volume $\left(\mathrm{dm}^{3}\right)$ & Survival \% & Plot CV $\mathrm{Ht}^{2}$ \\
\hline I-VA \& North. NC & 53 & $5.6 \pm .07$ & $18 \pm 0.9$ & $93.1 \pm 0.6$ & 5.7 \\
3-Coastal SC & 34 & $7.2 \pm .20$ & $37 \pm 2.7$ & $91.4 \pm 0.8$ & 6.0 \\
4-Coastal GA\&FL & 19 & $5.8 \pm .22$ & $18 \pm 1.9$ & $91.4 \pm 1.0$ & 7.3 \\
5-Lower Gulf & 44 & $6.6 \pm .10$ & $26 \pm 1.1$ & $89.7 \pm 0.8$ & 6.3 \\
6-Upper Guif & 35 & $6.7 \pm .11$ & $28 \pm 1.5$. & $90.6 \pm 0.9$ & 5.3 \\
7-Pied. SC\&GA & 80 & $6.0 \pm .08$ & $21 \pm 0.8$ & $90.4 \pm 0.5$ & 5.8 \\
\hline Overall & 265 & $6.2 \pm .06$ & $24 \pm 0.7$ & $91.0 \pm 0.3$ & 5.9 \\
\hline
\end{tabular}

${ }^{1}$ State abbreviations are VA: Virginia, NC: North Carolina, SC: South Carolina, GA: Georgia, FL: Florida.

${ }^{2}$ Plot CV Ht $(\%)=$ Coefficient of variation $(\mathrm{CV})$ for block $\mathrm{x}$ family interaction for height. 
phenotypic variance: $h^{2}{ }_{N S}=\sigma^{2}{ }_{\mathrm{A}} /\left(2 \sigma_{\mathrm{g}}^{2}+\sigma_{\mathrm{s}}^{2}+2 \sigma_{\mathrm{gt}}^{2}+\sigma^{2}{ }_{\mathrm{st}}+\right.$ $\left.\sigma_{p}^{2}+\sigma_{e}^{2}\right)$. Broad-sense heritability was estimated as the ratio of total genetic variance and phenotypic variance: $h^{2}{ }_{B S}=\left(\sigma^{2}{ }_{\mathrm{A}}+\sigma_{\mathrm{D}}^{2}\right) /\left(2 \sigma^{2}+\sigma_{\mathrm{s}}^{2}+2 \sigma^{2}{ }_{\mathrm{gt}}+\sigma^{2}{ }_{\mathrm{st}}+\sigma^{2}{ }_{\mathrm{p}}+\sigma^{2}{ }_{\mathrm{e}}\right)$. The type B genetic correlations for GCA and SCA effects as the genetic correlation of the same trait in different environments were estimated as $\mathrm{r}_{\mathrm{GCA}}=\sigma^{2}{ }_{\mathrm{A}} /\left(\sigma_{\mathrm{AxE}}^{2}+\sigma_{\mathrm{A}}^{2}\right)$ and $\mathrm{r}_{\mathrm{SCA}}=\sigma^{2}{ }_{\mathrm{NA}} /\left(\sigma^{2}{ }_{\mathrm{NAxE}}+\sigma^{2}{ }_{\mathrm{NA}}\right)$ (BURDON, 1977; FERNANDO et al., 1984). Data obtained from this study are variance components and their functions (heritabilities and genetic correlations) resulting from analysis of 265 diallel series in six test areas (Table 1 and Figure 1) of the North Carolina State University Industry Cooperative Tree Improvement Program.

\section{Statistical analysis}

Basic statistics for all measured traits, and genetic parameters were calculated for each of the six test areas in the Cooperative. These are relatively small, homogeneous geographic regions where all tests share common check seedlots (ANONYMOUS, 1984). Measurement and analyses were completed in 265 test series at age 6 (Table 1). From the analysis of each test series, the variance due to block $\mathrm{x}$ family interaction within each test (e.g. the variance of the $P_{i j o k l}$ or random plot effect from model 1) was used as an estimate of the precision for a given test series. The block $\mathrm{x}$ family variance was standardized as a coefficient of variation (CV) for each test series to minimize scale effects. Plot-to-plot $\mathrm{CV}$ values for height for six test areas appear in Table 1.

The response variables were genetic variances due to general $\left(\sigma^{2}{ }_{\mathrm{g}}\right)$ and specific combining ability $\left(\sigma^{2}{ }_{\mathrm{s}}\right)$, narrow-sense heritability $\left(h^{2}{ }_{N S}\right.$, ) and broad-sense heritability $\left(h^{2}{ }_{B S}\right)$, and type B genetic correlations $\left(\mathrm{r}_{\mathrm{GCA}}, \mathrm{r}_{\mathrm{SCA}}\right)$ for height and volume. Descriptive statistics of genetic variances, heritabilities and type $\mathrm{B}$ genetic correlations were produced for each test area using the UNIVARIATE procedure of SAS (SAS InstiTUTE INC., 1996). For each test area, the means and standard error of the means for heritabilities and genetic correlations were produced using the MEANS procedure of SAS (SAS INSTITUTE INC., 1996). To determine the effect of average test series height, survival, and CV on estimates of heritabilities, correlations among test series averages were calculated using the CORR procedure in SAS (SAS INSTITUTE INC., 1996).

Another way to evaluate the importance of $\mathrm{GxE}$ is to compare its variance to the genetic variance. The ratio of the genotype $\mathrm{x}$ environmental $(\mathrm{GxE})$ interaction variance over the genetic variance may be referred to as the K-statistic (McKEAND et al., 1997b). The K statistics for unrelated half-sib families $\left(\mathrm{K}_{\mathrm{hs}}\right)$ and for unrelated fullsib families were estimated as follows:

$$
\begin{aligned}
& \mathrm{K}_{\mathrm{hs}}=\sigma_{\mathrm{AxE}}^{2} / \sigma_{\mathrm{A}}^{2} \\
& \mathrm{~K}_{\mathrm{fs}}=\left(\sigma^{2}{ }_{\mathrm{AxE}}+1 / 2 \sigma^{2}{ }_{\mathrm{NAxE}}\right) /\left(\sigma_{\mathrm{A}}^{2}+1 / 2 \sigma^{2}{ }_{\mathrm{NA}}\right)
\end{aligned}
$$

This is a particularly meaningful measure of genotype by environment interaction when the environments investigated are considered to be a random sample from a larger set. The smaller the $\mathrm{K}$ statistic, the lower is the family by environment interaction. For this case, the K- statistic may be interpreted as the proportional amount by which the expected genetic variance within environments is greater than the genetic variance measured over environments. Such an interpretation follows from theory developed by YAMADA (1962) and COCKERHAM (1963) which implies that the genotype $\mathrm{x}$ environment interaction variance can be expressed as:

$$
\sigma_{\mathrm{GE}}^{2}=\mathrm{E}\left[\sigma_{\mathrm{g}}^{2}\right]-\sigma_{\mathrm{G}}^{2}
$$

where $\mathrm{E}\left[\sigma_{\mathrm{g}}^{2}\right]$ indicates expectation over environments of genetic variance within environments, and $\sigma^{2}{ }_{G}$ represents genetic variance determined over environments.

The K-statistic varies inversely with the intraclass correlation $t$ as described by DICKERSON (1962) and YAMADA (1962).

$$
\mathrm{t}=\sigma_{\mathrm{G}}^{2} /\left(\sigma_{\mathrm{G}}^{2}+\sigma_{\mathrm{GE}}^{2}\right)
$$

The intraclass correlation is sometimes used as a lower bound for the expected genetic correlation for a trait measured on relatives in two different environments (e.g. the type B genetic correlation of BURDON, 1977).

The heritability and type B genetic correlations estimated from individual test series are biased because they are not random samples derived from a population but are based on ratios of specific variance components from a test series (IsIK et al., 2005). Unbiased estimates of heritabilities and type $\mathrm{B}$ genetic correlations can be estimated using the first order of the variance components estimated for each test region as suggested by (IsIK et al., 2005).

$$
\begin{aligned}
& \mathrm{h}_{\mathrm{NS}-}^{2} \text { un }=4 \bar{\sigma}_{\mathrm{g}}^{2} /\left(2 \bar{\sigma}_{\mathrm{g}}^{2}+\bar{\sigma}_{\mathrm{s}}^{2}+2 \bar{\sigma}_{\mathrm{ge}}^{2}+\bar{\sigma}_{\mathrm{se}}^{2}+\bar{\sigma}_{\mathrm{p}}^{2}+\bar{\sigma}_{\mathrm{e}}^{2}\right) \\
& \mathrm{H}_{\mathrm{BS}-}^{2} \mathrm{un}=4\left(\bar{\sigma}_{\mathrm{g}}^{2}+\bar{\sigma}_{\mathrm{s}}^{2}\right) /\left(2 \bar{\sigma}_{\mathrm{g}}^{2}+\bar{\sigma}_{\mathrm{s}}^{2}+2 \bar{\sigma}_{\mathrm{ge}}^{2}+\bar{\sigma}_{\mathrm{se}}^{2}+\bar{\sigma}_{\mathrm{p}}^{2}+\bar{\sigma}_{\mathrm{e}}^{2}\right) \\
& \mathrm{r}_{\mathrm{GCA}-} \mathrm{un}=\bar{\sigma}_{\mathrm{g}}^{2} /\left(\bar{\sigma}_{\mathrm{g}}^{2}+\bar{\sigma}_{\mathrm{ge}}^{2}\right) \\
& \mathrm{r}_{\mathrm{SCA}-} \mathrm{un}=\bar{\sigma}_{\mathrm{s}}^{2} /\left(\bar{\sigma}_{\mathrm{s}}^{2}+\bar{\sigma}_{\mathrm{se}}^{2}\right)
\end{aligned}
$$

Where the sigma square bar indicates that the estimate is averaged over all test series in a region. These estimates are considered 'true' unbiased values for each region (IsIK et al., 2005). Since the variance components are considered a random sample for a test region, the means are $\mu_{x i}=\mu_{x j}=\mu_{x}$, and their variances would be $\sigma^{2}\left(\mu_{x i}\right)=\sigma^{2}\left(\mu_{x j}\right)=\sigma^{2}\left(\mu_{x}\right)$, and there is no covariance between the means (LYNCH and WALSH, 1998). Thus, the sampling variance of the unbiased mean (i.e., unbiased heritability) would be $\operatorname{Var}\left(\mathrm{h}_{\mathrm{NS} \text { _un }}^{2}\right)=\operatorname{Var}\left(4 \bar{\sigma}_{\mathrm{g}}^{2}\right) /\left(\overline{\boldsymbol{\sigma}}_{\mathrm{phen}}^{2}\right)^{2}$, where $\operatorname{Var}\left(4 \bar{\sigma}_{\mathrm{g}}^{2}\right)$ the is the average of variance of genetic variance for a given test region. The standard error of the mean would be the square root of the variance.

The impact of site preparation on test quality was determined by comparing a subset of tests established on cutover forested versus agricultural old-field sites for average height, survival, and the $\mathrm{CV}$ for height on a block by family basis. Cooperators were encouraged to establish diallel tests on agricultural sites, and this comparison allowed us to determine if there was any benefit to this practice. Detailed site information was available for 364 individual tests; 141 on cutover sites versus 223 on agricultural fields. 


\section{Results and Discussion}

\section{Descriptive statistics of traits for each test area}

Overall, trees averaged 6.24 meters in height and $24.2 \mathrm{dm}^{3}$ (cubic decimeters) in volume at age 6 years (Table 1). Survival was generally high, averaging $91 \%$ across al the test regions. The range of height means for individual test regions was large. Average height varied from $5.6 \mathrm{~m}$ to $7.2 \mathrm{~m}$ and average volume from $18 \mathrm{dm}^{3}$ to $37 \mathrm{dm}^{3}$ per tree. The largest trees were in the Coastal Plain of South Carolina with an average of $7.2 \mathrm{~m}$ and the smallest in the Virginia and northern North Carolina tests $(5.6 \mathrm{~m})$. Test regions had similar survival percentages. Survival ranged from 89.7 (Lower Gulf) to 93\% (Virginia and Northern North Carolina). The plotto-plot coefficients of variation (block $\mathrm{x}$ family interaction term) reflect the within-block homogeneity of the progeny tests. The test sites in the Georgia-Florida Coastal Test Area had on average higher coefficients than other regions (Table 1). The average for this area was $7.3 \%$, whereas the average coefficient for other areas ranged from $5.3 \%$ (Upper Gulf) to $6.3 \%$ (Lower Gulf).

\section{Distribution of genetic parameters}

Whisker-box plots of GCA and SCA genetic variances, narrow-sense heritability and type $\mathrm{B}$ additive genetic correlations are given in Figure 2. The small square in the box is the mean; the horizontal line inside the box is the median of the distribution. When the mean and the median overlap, the distribution is not skewed. In general, GCA and SCA variances and individual tree nar-
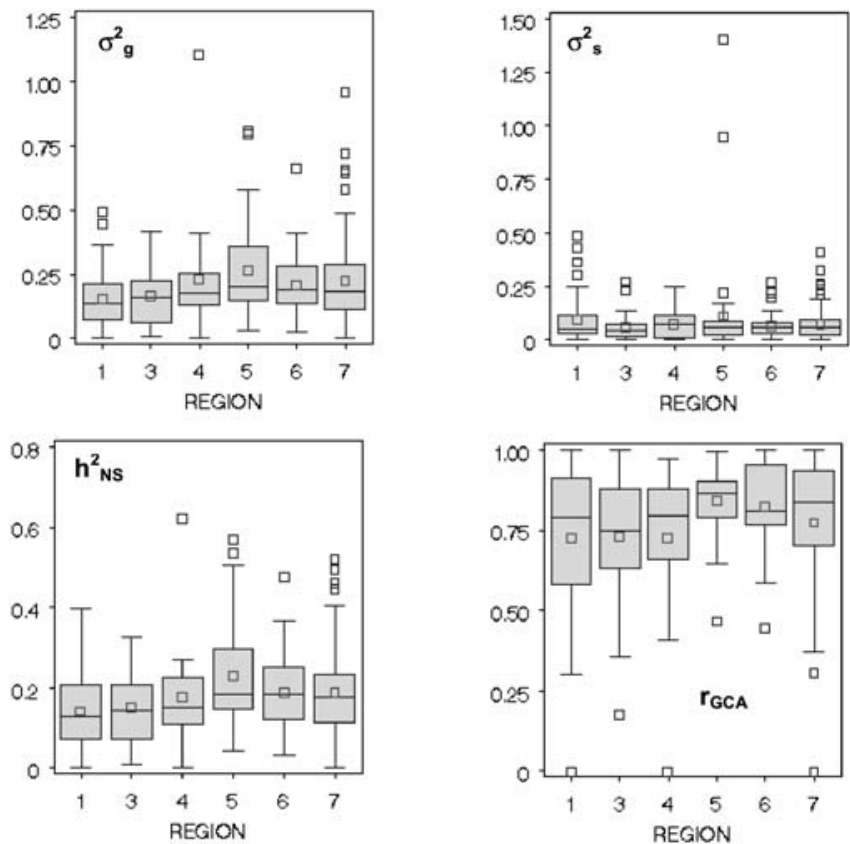

Figure 2. - Whisker plots of general combining ability variance $\left(\sigma^{2}\right)$, specific combining ability variance $\left(\sigma^{2}\right)$, narrow-sense heritability $\left(\mathrm{h}^{2}{ }_{\mathrm{NS}}\right)$ and type $\mathrm{B}$ genetic correlation $\left(\mathrm{r}_{\mathrm{GCA}}\right)$ for height in different breeding populations of loblolly pine. The line in the middle of the box is the median, the filled circle is the mean. The upper and lower limits of the box are the $3^{\text {rd }}$ and $1^{\text {st }}$ quartiles. The squares outside the line extending from the $1^{\text {st }}$ and $3^{\text {rd }}$ quartiles are outliers. row-sense heritabilities were skewed upward (high estimates). Additive genetic correlation was typically skewed towards lower end of the distribution. Skewness in GCA variance and thus in heritability was highest in the Lower Gulf (test area 5). There were several outliers for all the genetic parameters in all six test regions. We considered values greater or smaller than three times of interquartile range as outliers (SAS INSTITUTE INC., 1996). The extreme outliers (values greater or smaller than three times of interquartile range) were removed before calculation of descriptive statistics. The possible causes of extreme outliers are numerous. The sampling effect of parents may result in estimates outside of the theoretical expectations of variances due to 'bottle neck' (HILL, 1985). Several factors such as tree mortality, test quality and damage caused by extreme climatic events may lead to extreme values of estimates of variances, but we could find no reason for these extreme values.

\section{Heritabilities for height and volume}

The individual-tree narrow-sense heritability for height averaged 0.18 and varied from a low of 0.15 in region 1 (Virginia and North Carolina) tests to a high of 0.23 in the Lower Gulf trials (Table 2). Heritabilities estimated from different diallel series in a test region varied considerably. The highest $h^{2}{ }_{N S}$ estimate for height in a test series was 0.62 , and the lowest was 0.01 (data not presented). Broad-sense heritabilities were higher than narrow-sense heritabilities due to the presence of non-additive genetic variance for height. Overall, the ratio of non-additive to additive genetic variance was 0.59 , so the $\mathrm{H}^{2}$ BS was 0.25 or $39 \%$ greater than the $\mathrm{h}^{2}{ }_{\mathrm{NS}}$ for height. There was relatively little regional variation in $\mathrm{H}^{2}{ }_{\mathrm{BS}}$, but the highest variation in a heritability was found in regions 4 and 5 (Coastal GA-FL and Lower Gulf) as shown by the higher standard error of the mean (0.03) in these regions. Broad-sense heritability estimates for height in a test series ranged from 0.05 to 1.0 (data not presented). The cause of very small and very high $\mathrm{h}^{2}$ estimates could be due to the sampling effect of genotypes and/or environmental factors.

Similar heritability estimates were found for average stem volume as were found for height. The individualtree narrow-sense heritability for volume averaged 0.16 , slightly lower than for height, and the range in heritability estimates across regions was not as great for volume compared to height, ranging from a low of 0.12 to a high of 0.18 . The highest $\mathrm{h}^{2}$ NS estimate for volume in a test series was 0.58 and the lowest was 0 (data not presented). Broad-sense heritabilities for volume were slightly higher (average $\mathrm{H}^{2}{ }_{\mathrm{BS}}=0.22$ ) than narrow-sense heritabilities. Overall, the ratio of non-additive to additive genetic variance was slightly higher for volume (0.83) than for height (0.59), indicating a relatively greater amount of non-additive genetic variance for volume. There was slightly more regional variation in $\mathrm{H}^{2}{ }_{\mathrm{BS}}$ compared to $\mathrm{h}^{2}$ NS for volume, but the range in values was only from 0.17 to 0.25 .

The unbiased individual-tree narrow sense and broadsense heritabilities are given in Table 3. In general, the unbiased estimates were parallel to the simple averages for each region, except for region 4 (Coastal Georgia and 
Table 2. - The mean heritabilities and type-B genetic correlations in six test areas in the southeastern United States. The descriptive statistics were obtained after removing outliers from the data set. All are mean values across test sites within a test series.

a) Height

\begin{tabular}{lccccc} 
NCSL Test Area & $N$ & $\mathrm{~h}^{2}{ }_{\mathrm{NS}} \pm \mathrm{se}$ & $\mathrm{H}^{2}$ rss $\pm \mathrm{se}$ & $\mathrm{r}_{\mathrm{Gr}} \pm \mathrm{se}$ & $\mathrm{r}_{\mathrm{SCA}} \pm \mathrm{se}$ \\
1-VA \& North NC & 53 & $0.15 \pm .01$ & $0.23 \pm .02$ & $0.77 \pm .03$ & $0.72 \pm .04$ \\
3-Coastal SC & 34 & $0.15 \pm .01$ & $0.20 \pm .02$ & $0.73 \pm .03$ & $0.82 \pm .05$ \\
4-Coastal GA\&FL & 19 & $0.19 \pm .03$ & $0.25 \pm .03$ & $0.76 \pm .04$ & $0.83 \pm .06$ \\
5-Lower Gulf & 44 & $0.23 \pm .02$ & $0.32 \pm .03$ & $0.84 \pm .02$ & $0.77 \pm .05$ \\
6-Upper Gulf & 35 & $0.19 \pm .02$ & $0.25 \pm .02$ & $0.83 \pm .02$ & $0.71 \pm .04$ \\
7-Pied. SC\&GA & 80 & $0.20 \pm .01$ & $0.25 \pm .01$ & $0.80 \pm .02$ & $0.69 \pm .04$ \\
\hline Overall & 265 & $0.18 \pm .01$ & $0.25 \pm .01$ & $0.77 \pm .01$ & $0.69 \pm .02$ \\
\hline
\end{tabular}

b) Volunte

\begin{tabular}{lccccc}
\hline NCSL Test Area & $\mathrm{N}$ & $\mathrm{h}^{2} \mathrm{Ns} \pm \mathrm{se}$ & $\mathrm{H}_{\mathrm{BS}}^{2} \pm \mathrm{se}$ & $\mathrm{r}_{\mathrm{GCA}} \pm \mathrm{se}$ & $\mathrm{rec}_{\mathrm{sen}}$ \\
\hline 1-VA\& North. NC & 50 & $0.13 \pm .01$ & $0.21 \pm .02$ & $0.77 \pm .03$ & $0.73 \pm .04$ \\
3-Coastal SC & 32 & $0.12 \pm .01$ & $0.17 \pm .01$ & $0.72 \pm .04$ & $0.80 \pm .05$ \\
4-Coastal GA\&FL & 18 & $0.13 \pm .03$ & $0.19 \pm .03$ & $0.65 \pm .05$ & $0.76 \pm .06$ \\
5-Lower Gulf & 44 & $0.17 \pm .01$ & $0.25 \pm .02$ & $0.80 \pm .02$ & $0.81 \pm .03$ \\
6-Upper Gulf & 35 & $0.16 \pm .01$ & $0.21 \pm .01$ & $0.77 \pm .02$ & $0.68 \pm .05$ \\
7-Pied. SC\&GA & 78 & $0.18 \pm .01$ & $0.24 \pm .01$ & $0.75 \pm .02$ & $0.70 \pm .04$ \\
Overall & 257 & $0.16 \pm .01$ & $0.22 \pm .01$ & $0.75 \pm .01$ & $0.74 \pm .02$
\end{tabular}

$\mathrm{h}^{2}{ }_{\mathrm{NS}}=$ individual-tree narrow-sense heritability.

$\mathrm{H}^{2}{ }_{\mathrm{BS}}=$ individual-tree broad-sense heritability.

$\mathrm{r}_{\mathrm{GCA}}=$ type $\mathrm{B}$ genetic correlation (GCA) across test sites within a series.

$\mathrm{r}_{\mathrm{SCA}}=$ type $\mathrm{B}$ genetic correlation (SCA) across test sites within a series.

Florida). The biased and unbiased $\mathrm{h}^{2}{ }_{\mathrm{NS}}$ for height was 0.15 versus 0.19 , respectively, in the region 4 . The difference between biased (0.13) and unbiased (0.10) $\mathrm{H}^{2}$ BS for volume was smaller in that region. The cause of odd estimates (i.e., heritability greater than 1.0) could be explained by the sampling effect of genotypes and environmental factors. The unbiased heritability estimates for region 4 also had greater standard errors compared to other regions.

These estimates for narrow-sense and broad-sense heritabilities are fairly typical of what has been found for growth traits for various tree species (e.g. CoRNELIUS, 1992 for $\mathrm{h}^{2}{ }_{\mathrm{NS}}$ estimates). Parent trees for each test series originated from a relatively narrow geographic region, typically within each of the test areas described in Tables 1 and 2. Had selections from a wider geographic region been bred together in the diallels for a test series, the genetic variation would have been greater due to the large geographic genetic variation in loblolly pine (e.g. Schmidtling, 2001). Summarizing genetic parameters from 105 diallel test series of loblolly pine, IsIK et al. (2005) also reported a wide range of heritability estimates. Partitioning parents of a tree breeding population into smaller groups, such as diallels, for mat- ing and testing is a common practice due to logistic constraints (YANCHUK, 1996; JOHNSON and KING, 1996). Thus, variance components may vary dramatically from one diallel test series to another, as reported in the literature (YeH and Heaman, 1987; CoRnelius, 1992). The fluctuation in genetic variances and thus in their functions is mainly due to 'bottleneck' of random sampling of small groups of parents from the population (HILL, 1985; IsIK et al., 2005). Since the heritability estimates are based on such large number of genotypes, they could be assumed random samples of loblolly pine breeding populations. Then, the overall averages could be considered as populations' approximate means and could be used for genetic gain estimates and planning of future breeding programs.

\section{Progeny test quality}

A common measure used to evaluate test quality and precision is the block $\mathrm{x}$ family (plot) term coefficient of variation $(\mathrm{CV})$. Values below 8 to $10 \%$ for height at age six years are very acceptable and indicate high precision in a testing program. Overall, the average CV was $5.9 \%$, with a low of $5.3 \%$ in the Upper Gulf and a high of $7.3 \%$ in the Coastal Georgia and Florida trials. Cooperators 
Table 3. - The unbiased mean heritabilities and type B genetic correlations in six test areas in the southeastern United States.

a) Height

\begin{tabular}{|c|c|c|c|c|}
\hline NCSL: Test AIea & $\mathrm{h}_{\text {unl }}^{2} \pm \mathrm{se}$ & $\mathrm{H}^{2}{ }_{\text {un } b} \pm \mathrm{se}$ & $\mathrm{I}_{6 \mathrm{CA}_{-} \text {untili }} \pm \mathrm{se}$ & IbCA unl $\pm \mathrm{se}$ \\
\hline l-VA\& North. NC & $0.15 \pm .0]$ & $0.22 \pm .02$ & $0.80 \pm .03$ & $0.70 \pm .04$ \\
\hline 3-Coastal SC & $0.16 \pm .01$ & $0.21 \pm .02$ & $0.76 \pm .03$ & $0.73 \pm .05$ \\
\hline 4-Coastal GA\&FL & $0.15 \pm .03$ & $0.21 \pm .03$ & $0.75 \pm .04$ & $0.72 \pm .06$ \\
\hline 5-[.ower Gulf & $0.22 \pm .02$ & $0.28 \pm .03$ & $0.85 \pm .02$ & $0.73 \pm .05$ \\
\hline 6-Upper Gulf & $0.19 \pm .02$ & $0.26 \pm .02$ & $0.84 \pm .02$ & $0.69 \pm .04$ \\
\hline 7-Pied. SC\&GA & $0.19 \pm .01$ & $0.25 \pm .01$ & $0.81 \pm .02$ & $0.64 \pm .04$ \\
\hline Overall & 0.19 & 0.24 & 0.80 & 0.70 \\
\hline
\end{tabular}

b) Volume

\begin{tabular}{|c|c|c|c|c|}
\hline NCSL Test Area & $\mathrm{h}^{2}{ }_{\text {шाi }} \pm \mathrm{sc}$ & $\mathrm{H}^{2}{ }_{\mathrm{unb}} \pm \mathrm{sc}$ & $\mathrm{r}_{\mathrm{GCCA}_{2} \mathrm{unb}} \pm \mathrm{se}$ & $\mathrm{r}_{\mathrm{SC} \mathrm{A} \text { шा }} \pm \mathrm{se}$ \\
\hline I-VA \& North. NC & $0.14 \pm .01$ & $0.21 \pm .02$ & $0.78 \pm .03$ & $0.73 \pm .04$ \\
\hline 3-Coastal SC & $0.13 \pm .01$ & $0.18 \pm .01$ & $0.77 \pm .04$ & $0.77 \pm .05$ \\
\hline 4-Coastal GA\&FL & $0.10 \pm .03$ & $0.16 \pm .03$ & $0.67 \pm 05$ & $0.70 \pm .06$ \\
\hline 5-L.ower Gulf & $0.18 \pm .01$ & $0.23 \pm .02$ & $0.83 \pm 02$ & $0.71 \pm .03$ \\
\hline 6-Upper Gulf & $0.16 \pm .01$ & $0.22 \pm .01$ & $0.78 \pm .02$ & $0.67 \pm .05$ \\
\hline 7-Pied. SC\&GA & $0.17 \pm .01$ & $0.23 \pm .01$ & $0.79 \pm .02$ & $0.66 \pm .04$ \\
\hline Ovetall & 0.16 & 0.22 & 0.79 & 0.69 \\
\hline
\end{tabular}

put a tremendous amount of effort in finding uniform test sites for the $2^{\text {nd }}$-generation and plantation-selection testing program. The high-quality data and breeding values that we have today is a direct result of these efforts.

There was a highly significant difference between cutover forested sites and agricultural sites for test precision (coefficients of variation for plot-to-plot mean squares) (T-test $\operatorname{Pr}<0.001)$. Tests established on agricultural fields had average block $x$ family CV's of $5.6 \%$ for 6 -year height, and tests on cutover sites had CV's of $7.0 \%$. There are many reasons why some test sites had higher CV's than others. Lower Coastal Plain sites with spodic soils and steep Piedmont sites proved to be particularly difficult to manage for test uniformity. Additionally, there were meaningful differences between organizations as to the resources devoted to site preparation and test management. With all these confounded and conflicting factors, no one cause for test uniformity or variation can be identified. However, there is little doubt that tests planted on agricultural sites were more uniform and yield better-quality data (Table 1). Results for the small number of first-generation coastal Douglas-fir (Pseudotsuga menziessi (Mirb.) Franco) tests established on ex-agricultural sites in the Pacific North- west also suggest such sites have resulted in good heritabilities (K. JAYAWICKRAMA, unpublished data). The slash pine (Pinus elliottii Engelm.) breeding program in Florida appears to have improved heritabilities by a factor of two or three from the first cycle of breeding to the second cycle, through a combination of better silvicultural treatments and better field designs (HUBER et al., 2003).

We did not compare heritability estimates for cutover and agricultural sites since heritabilities were estimated across four test sites for a diallel series not for individual sites. In most cases, test series had both type of sites that did not allow a direct comparison of heritabilities.

\section{Relationships between genetic parameters and test characteristics}

Several informative relationships among progeny test characteristics and genetic parameters (heritability) were identified. The trends were very similar for both height and volume. For height, the individual-tree narrow sense heritability ranged between 0 and 0.62 , depending on the test series. Possible reasons for this wide range of estimates may include:

1) Genetic sampling: there were real differences in the genetic variances estimated from 265 diallel series. The 


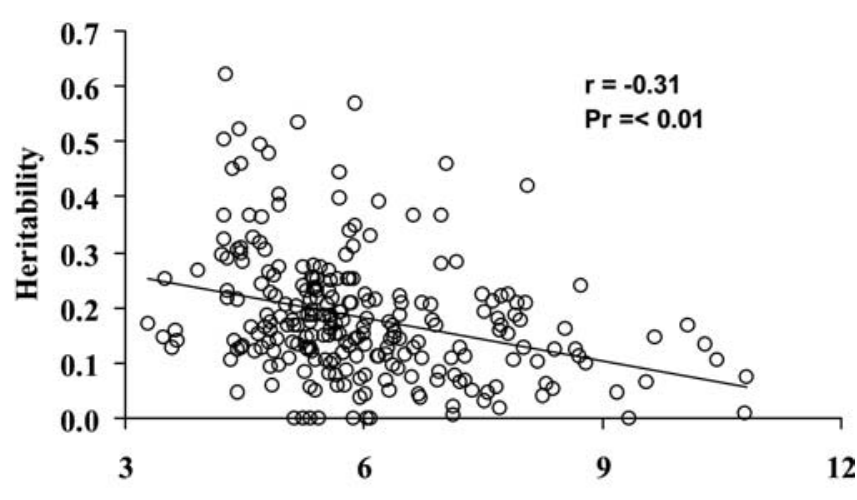

Average CV for Height in Test Series

Figure 3. - Relationship between estimates of individual-tree narrow-sense heritabilities for height at age 6 years and estimates of pooled coefficients of variation (block $\mathrm{x}$ family basis) for height for all 265 test series.

small sample size of 6 parents per diallel may have contributed to the high variation in genetic variances due to bottle neck or genetic sampling effect.

2) The variation in heritability estimates could be at least partially explained by variation in test attributes such as tree size, test precision (as measured by the CV based on block x family effects), and by average test survival.

The relationship between test precision (CV) and heritability was negative $(\mathrm{r}=-0.31)$ indicating that as the precision decreased, (greater CV values) heritability for height decreased (Figure 3). Survival had little effect on heritability estimates $(r=0.13$, but significant at $\mathrm{P}<0.03$ ), probably because the overall survival was very high $(91 \%)$, and the range in survival was fairly small. The poorest survival in a test series was $76 \%$, but only 5 of the 265 test series had survival below $80 \%$. Additionally, if survival in a block was below $75 \%$, we discarded it before analyzing the data. Therefore, the poorest surviving tests are not included in this analysis.

Although these relationships are not strong, they illustrate the value of maintaining minimum standards for survival and environmental uniformity in a tree breeding program. High survival and good test precision do not guarantee that heritability estimates will be high, since the effect of genetic sampling in the small diallels and test series can always be influential. Sometimes there are no genetic differences among 12 parents in a test series, and heritability will be zero. However, in tests that have large environmental variance and/or poor survival, genetic effects will very often be masked, and heritability will be low.

The average height for a test series varied by about three times (from $3.83 \mathrm{~m}$ to $9.57 \mathrm{~m}$ ) at age 6 years. Overall, there was a small, but significant, correlation $(r=0.17)$ between average height in a series and the estimate of narrow-sense heritability for height (Figure 4). There is a confounding effect in the correlation for $\mathrm{h}^{2}{ }_{\mathrm{NS}}$ since the heritabilities and average heights tend to vary concurrently across regions. For example, both $h^{2}{ }_{N S}$ and average height were high in the Lower Gulf and low in the northern tests (Region 1). When the relationship

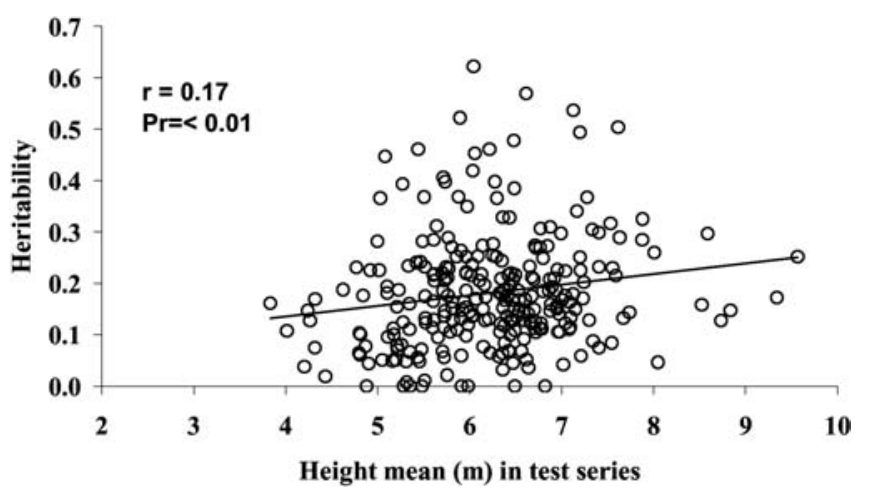

Figure 4. - Relationship between estimates of individual-tree narrow-sense heritabilities for height and average test height at age 6 years for all 265 test series.

between test height and $\mathrm{h}^{2}$ NS was assessed within a region, there was generally no significant correlation. One exception to this was in the Coastal South Carolina trials. There was a moderately strong positive correlation between height and $\mathrm{h}^{2}{ }_{\mathrm{NS}}(\mathrm{r}=0.60)$. Why this significant correlation occurred in Coastal SC is not clear, but in general, strong genetic effects were just as likely to exist on low site index sites as on high site index sites.

Estimated single-site heritabilites showed no association with site index in one summary of open-pollinated slash pine tests (HoDGE and WHITE, 1992). A study of full-sib tests suggested that within-site heritability estimates might be higher in high site-index tests than in low site-index sites $\left(\mathrm{h}_{2}=0.16\right.$ vs. $\left.\mathrm{h}_{2}=0.11\right)$, though the differences between high site-index and low site-index were not significant (DIETERs et al., 1995). An association between mean volume and heritability was suggested for tests of Pinus tecunumanii (HoDGE and DvORAK, 1999). A similar association between higher site means and higher within-site heritability is observed for coastal Douglas-fir in the US Pacific Northwest (K. JAYAWICKRAMA, unpublished data).

Relationships between different environments and heritability estimates have been extensively reviewed by HoFFMANN and MERILA (1999). The authors invoked several hypotheses to explain variation in heritability under different environments. They suggested that the underlying cause is changes in additive genetic variance, but no consistent effect of unfavorable conditions were found. Higher type-B genetic correlations were reported for Pinus elliottii between pairs of locations of similar site indices than between pairs of locations with very different site indices (HoDGE and WHITE, 1992). The authors attributed high genotype $\mathrm{x}$ environment interaction to differences in site quality, and suggested that large site index differences between progeny test sites and commercial production land will decrease the reliability of progeny test data in predicting breeding values.

\section{Genotype by environment interactions}

In past studies, we have seen very little evidence for important genotype by environment interaction $(\mathrm{GxE})$ for height or volume at the open-pollinated or half-sib family level for loblolly pine. For example, in a large series of trials, open-pollinated families were remark- 
ably stable across a wide range of sites that encompass large differences in site productivity (LI and McKEAND, 1989; McKeAND et al., 1990, 1997a). There have been some noted exceptions where $\mathrm{GxE}$ has been significant for different populations of loblolly pine (SIERRA-LUCERO et al., 2003; ATWOOD et al., 2002; YEISER et al., 2001), so a detailed assessment for these populations was warranted.

In the diallel tests, GxE for both half-sib and full-sib families can be assessed. Full-sib families are expected to display a higher degree of interaction with the environment than half-sib families since there is less genetic variance within each full-family (i.e., a lower level of buffering to environmental variations), and more of the genetic variance exists among families (e.g., ALLARD and BRADSHAW, 1964; BRIDGWATER and STONECYPHER, 1978). Additionally, GxE at the full-sib family level is caused by both additive and non-additive effects.

Type B genetic correlations give an indication of the importance of genotype by environment interaction. If the correlation is high (generally $>0.67$ ), then GxE is considered to be of minimal concern in breeding and deployment programs (SHELbOURNe, 1972). We estimated type B genetic correlations for both GCA (the most common type of estimate) and for SCA (Table 2). Overall, the average correlations were high $\left(\mathrm{r}_{\mathrm{GCA}}=0.77\right.$ and $\mathrm{r}_{\mathrm{SCA}}=0.69$ for height; $\mathrm{r}_{\mathrm{GCA}}=0.75$ and $\mathrm{r}_{\mathrm{SCA}}=0.74$ for vol ume), indicating a relative lack of $\mathrm{GxE}$ both for additive and non-additive genetic effects for growth traits. There were some test series with much lower type B genetic correlations (lowest was 0.04 , highest was 1.00 for both height and volume), but the average GxE was low. The unbiased additive and non-additive type $\mathrm{B}$ genetic correlations were very similar to the averages for each region (Table 3). Overall, higher unbiased estimates of additive genetic correlations suggest that genotype by environment interactions are negligible. For the $\mathrm{r}_{\mathrm{GCA}}$ for height, there were regional differences. Families were most stable in the Lower Gulf and Upper Gulf tests and slightly more interactive in the other regions. As found in numerous other trials (e.g. LI and McKEAND, 1989; McKeAND et al., 1997a; Yeiser et al., 1981), GxE appears to be of minimal concern for this large sample of families.

The average K-statistic for half-sibs (caused only by additive genetic $\mathrm{x}$ environmental interaction) was 0.35 for height and 0.52 for volume, meaning that the $\mathrm{GxE}$ variance was about one-third to one-half the genetic variance for height and volume, respectively. Again, the family by environment variance or specifically the additive genetic by environment variance is of little practical concern. Interestingly, the GxE for full-sibs (caused by both additive and non-additive genetic $\mathrm{x}$ environmental interaction) is essentially the same as for half-sibs for height $\left(\mathrm{K}_{\mathrm{fs}}=0.36\right)$ and was lower than $\mathrm{GxE}$ for half-sibs for volume $\left(\mathrm{K}_{\mathrm{fs}}=0.43\right.$ for full-sibs for volume). Since the non-additive by environment interaction is small (e.g., the large $\mathrm{r}_{\mathrm{SCA}}$ values in Table 3), full-sib families should be as stable and predictable across sites as half-sib families. With more emphasis on operational deployment of full-sib families (BRAMLETT, 1997), foresters should be able to plant well tested crosses with confidence in their performance across many sites.

The implications for deployment of both half-sib and full-sib families are clear. Full-sib families will be just as stable as half-sib families for growth traits across different sites, at least within a fairly narrow geographic region. More extensive testing of full-sib families across diverse geographic regions will be conducted by cooperators in the NCSU-ICTIP in the third-cycle breeding program. We are interested in determining the stability of full-sib families for growth traits, as well as for fusiform rust resistance and stem quality traits. GxE may well be an important concern when other traits besides height and volume are evaluated (e.g., McKEAND et al., 2003a) and when full-sib families are planted on more diverse sites across more diverse regions.

\section{Conclusions}

Analyses of the diallel data will continue to be more thoroughly investigated to assess $\mathrm{GxE}$, correlations among traits, and estimates of genetic gain for different traits. This is a unique data set because of the size of the genetic sample (over 3000 parent trees) and the high quality of the test information. In summary, the analyses of 265 diallel test series have led to several valuable conclusions for future testing efforts:

1. The $\mathrm{h}^{2}$ NS estimates for height and for volume were 0.19 and 0.16 , respectively for loblolly pine. The $\mathrm{h}^{2}{ }_{\mathrm{BS}}$ estimates were higher for height (0.24) and volume (0.22) due to presence of non-additive genetic variances. These estimates are based on over one million trees and could be used for designing breeding programs and prediction of genetic gains for breeding programs.

2. Planting tests on uniform sites is important if reasonable levels of heritability and genetic gains are to be achieved.

3. In general, genetic differences in growth traits are not strongly related to site index. Growth potential for a given site is not a critical determinant for use as a test site.

4. GxE interaction effects are relatively minor both for half-sib and full-sib families.

\section{Acknowledgments}

This work was made possible by the many years of support by members of the North Carolina State University Industry Cooperative Tree Improvement Program; the Department of Forestry and Environmental Resources, NCSU; McIntire-Stennis Project NCZ04187; and the Agricultural Research Service, NCSU. In particular, we appreciate the contributions of previous Cooperative staff members, especially Robert WeIr, Alice Hatcher, J. B. JeTt, and JERRY SPRAGUE.

\section{References}

Allard, R. W. and A. D. BradshaW (1964): Implications of genotype-environmental interactions in applied plant breeding. Crop Sci. 4: 503-508. 
AnONYMous (1984): $28^{\text {th }}$ Annual Report. N.C. State University-Industry Cooperative Tree Improvement Program. $68 \mathrm{p}$.

Atwood, R. A., T. L. White and D. A. Huber (2002): Genetic parameters and gains for growth and wood properties in Florida source loblolly pine in the southeastern United States. Can. J. For. Res. 32: 1025-1038.

BRAMLETT, D. L. (1997): Genetic gain from mass controlled pollination and topworking. J. For. 95: 15-19.

Bridgwater, F. E. and R.W. Stonecypher (1978): Genotype $\mathrm{x}$ environment interaction: implications in tree breeding programs. pp. 46-63. In: Proceedings of $5^{\text {th }}$ North American Forest Biology Workshop edited by C. A. Hollis and A. E. Squillace. Univ. Florida, Gainesville, FL.

BuRDON, R. D. (1977): Genetic correlation as a concept for studying genotype-environment interaction in forest tree breeding. Silvae Genet. 26: 145-228.

CockerHAM, C. C. (1963): Estimation of genetic variances. pp. 53-94. In: Statistical Genetics and Plant Breeding, edited by W. D. HANSON and H. F. RoBInson. National Academy of Sciences, National Research Council. $982 \mathrm{pp}$

CoRnEliUs, J. (1992): Heritabilities and additive genetic coefficients of variation in forest trees. Can. J. For. Res. 24: 372-379.

DiCKERSON, G. E. (1962): Implications of genetic-environmental interaction in animal breeding. Animal Production 4: 47-63.

Dieters, M. J., T. L White and G. R. Hodge (1995): Genetic parameter estimates for volume from full-sib tests of slash pine (Pinus elliottii). Can. J. For. Res. 25 1397-1408.

Fernando, R. L., S. A. Knights and D. Gianola (1984): On a method of estimating the genetic correlation between characters measured in different experimental units. Theor. Appl. Genet. 67: 175-178.

Goebel, N. B. and J. R. WARNER (1966): Volume tables for small diameter loblolly pine, shortleaf and Virginia pine in the upper South Carolina Piedmont. Forest Research Series No. 7, Clemson Univ., Clemson, SC.

HILL, W. G. (1985): Effect of population size on response to short term and long term selection. J. of Animal Breeding Genet. 102: 161-173.

Hodge, G. R. and W. S. DvoraK (1999): Genetic parameters and provenance variation of Pinus tecunumanii in 78 international trials. For. Genet. 6(3): 157-180.

Hodge, G. R. and T. L. White (1992): Genetic parameter estimates for growth traits at different ages in slash pine and some implications for breeding. Silvae Genet. 41: 252-262.

Hoffmann, A. A. and J. Merilä (1999): Heritable variation and evolution under favourable and unfavourable conditions. TREE 14: 96-101.

Huber, D. A., T. L. White and G. L. Powell (2003): Agefive results from the cooperative forest genetics research program slash pine polymix trials. P. 38-43. Proc. 27 ${ }^{\text {th }}$ Southern Forest Tree Improvement Conference, Oklahoma State University, Stillwater, Oklahoma, USA. June 24-27, 2003.

IsIK, F., D. D. Boos and B. LI (2005): The distribution of genetic parameter estimates and confidence intervals from small disconnected diallels. Theor. Appl. Genet. 110: $1236-1243$.

JAYAWICKRAMA, K. J. S. (2001): Genetic parameter estimates for radiata pine in New Zealand and New South Wales: a synthesis of results. Silvae Genet. 50: 45-53.
Johnson, G. R. and J. N. KING (1998): An analysis of halfdiallel mating designs. Silvae Genet. 47: 74-79.

LI, B. and S. E. McKeAND (1989): Stability of loblolly pine families in the southeastern U.S. Silvae Genet. 38: 96-101.

LI, B., S. E. McKeAND and R. J. WeIR (1996): Genetic parameter estimates and selection efficiency for the loblolly pine breeding program in the southeastern U.S. P. 164-168. In: Dieters, M. J., MAtheson, A. C., NikLes, D. G., Harwood, C. E. and Walker, S. M. (eds.). Tree Improvement for Sustainable Tropical Forestry. Proc. QFRI-IUFRO Conf. Caloundra, Queensland, Australia. 27 Oct. -1 Nov., 1996.

Lopez-Upton, J., T. L White and D. A. Huber (1999): Effects of site and intensive culture on family differences in early growth and rust incidence of loblolly and slash pine. Silvae Genet. 48: 284-293.

LYNCH, M. and B. WALSH (1998): Genetics and analysis of quantitative traits. Sinauer Associates, Inc., Sunderland, MA 980P

MCKEAND, S. E. (1988): Optimum age for family selection for growth in genetic tests of loblolly pine. For. Sci. 34: 400-411.

McKeand, S. E., H. V. Amerson, B. Li and T. J. Mullin (2003a): Families of loblolly pine that are most stable for resistance to fusiform rust are the least predictable. Can. J. For. Res. 33: 1335-1339.

McKeand, S. E., R. P. Crook and H. L. Allen (1997a): Genotypic stability effects on predicted family responses to silvicultural treatments in loblolly pine. South. J. Appl. For. 21: 84-89.

MCKeAND, S. E., G. ERIKSson and J. H. Roberds (1997b): Genotype by environment interaction for index traits that combine growth and wood density in loblolly pine. Theo. Appl. Genet. 94: 1015-1022.

McKeand, S. E., B. Li, A. V. Hatcher and R. J. Weir (1990): Stability parameter estimates for stem volume for loblolly pine families growing in different regions in the southeastern United States. For. Sci. 36: 10-17.

McKeand, S., T. Mullin, T. Byram, T. L. White (2003b): Deployment of genetically improved loblolly and slash pine in the South. J. For. 101: 32-37.

SAS Institute INC. (1996): SAS/STAT: Changes and enhancements (through release 6.11). Cary, NC.

Searle, S. R., G. Casella and C. E. McCulloch (1992): Variance components. John Wiley \& Sons Inc., New York, 501p.

Schmidtling, R. C. (2001): Southern pine seed sources. Gen. Tech. Rep. SRS-44. Asheville, NC: USDA, Forest Service, Southern Research Sta. 25p.

Shelbourne, C. J. A. (1972): Genotype-environment interaction: its study and its implications in forest tree improvement. In: Proc. IUFRO Genetics-SABRAO, Jt. Symp., Tokyo, Japan. B-1 (I): 1-28.

Sierra-Lucero, V., D. A. Huber, S. E. McKeand, T. L. White and D. L. Rockwood (2003): Genotype-by-environment interaction and deployment considerations for families from Florida provenances of loblolly pine. For. Genet. 10: 85-92.

TALBERT, J. T. (1979): An advanced-generation breeding plan for the N. C. State University-Industry Pine Tree Improvement Cooperative. Silvae Genet. 28: 72-75.

WeIR, R. J. and B. J. ZoBeL (1975): Managing genetic resources for the future, a plan for the N.C. State Industry Cooperative Tree Improvement Program. P. 73-82. In: Proc. 13 ${ }^{\text {th }}$ South. For. Tree Impr. Conf., Raleigh, NC. 
Woods, J. H., D. Kolotelo and A. D. YANChUK (1995): Early selection of coastal Douglas-fir in a farm-field test environment. Silvae Genet. 44: 178-186.

YAMADA, Y. (1962): Genotype by environment interaction and genetic correlation of the same trait under different environments. Jap. J. Genet. 37: 498-509.

YANCHUK, A. D. (1996): General and specific combining ability from disconnected partial diallels of coastal Douglas fir. Silvae Genet. 45: 37-44.

YEH, F. C. and J. C. HEAMAN (1987): Estimating genetic parameters of height growth in seven year-old coastal Douglas-fir from disconnected diallels. For. Sci. 33: 946-957.

Yeiser, J. L., W. Lowe and J. P. VAN BUIJTENEN (2001): Stability and seed movement for loblolly pine in the Western Gulf Region. Silvae Genet. 50: 81-88.
Yeiser, J. L., J. P. vAN BuiJtenen and W. J. Lowe (1981): Genotype $\mathrm{x}$ environment interactions and seed movement for loblolly pine in the Western Gulf Region. Silvae Genet. 36: 196-200.

XiANG, B. and B. Li (2001): A new mixed analytical method for genetic analysis of diallel data. Can. J. For. Res. 31: 2252-2259.

XIANG, B., B. Li and S. E. McKeand (2003a): Genetic gain and selection efficiency of loblolly pine in three geographic regions. For. Sci. 49: 196-208.

XIANG, B., B. LI and F. IsIK (2003b): Time trend of genetic parameters in growth traits of Pinus taeda L. Silvae Genet. 52: 114-121.

\title{
Genetic Variation in Reproductive Traits in a Clonal Seed Orchard of Prunus avium in Northern Spain
}

\author{
By R. DíAz ${ }^{*)}$ and E. MERLO \\ Departamento de Producción Forestal. Centro de Investigacións Ambientais de Lourizán, Apdo. 127, \\ Pontevedra, 36080 Spain
}

(Received $23^{\text {th }}$ October 2006)

\begin{abstract}
In the present study we investigated the reproductive phenology of Prunus avium in a seed orchard located in northwestern Spain. The study was carried out with 103 clones from 7 provenance regions in northern Spain. The most advanced flowering stage on different dates and the number of flowers and cherries were monitored over two consecutive years. Significant differences among clones were found for all of the studied traits, with high broad-sense heritability estimates for all, except duration of flowering and synchronization index, both of which showed moderate heritability. In general, there was good overall reproductive synchronization in the seed orchard, although two groups of clones were differentiated. Clones from two out of the seven populations studied flowered later and were less well synchronized. The clonal differentiation was correlated with geoclimatic variables, suggesting that clones from lower altitudes and higher temperatures tend to an earlier flowering.
\end{abstract}

Key words: Wild cherry, genetic variation, flowering, genetic parameters, reproductive synchronization, geographic pattern.

\section{Introduction}

Wild cherry is a very valuable forest tree species. The wood is mainly used for panelling and cabinet-making and achieves very high prices on the wood market. Breeding programmes have been initiated in several

\footnotetext{
*) Corresponding author: RAQUEL DÍAZ, Phone: +34-986805054, Fax: +34-986856420. E-mail: rdiaz.cifal@siam-cma.org
}

countries because of the value of the wood and the fast growth of the species (KoBLIHA, 2002). In Galicia (NW Spain) a long term breeding programme for this species was begun in the 1990's to improve timber quality and production. The breeding programme included phenotypic mass selection in wild stands and the use of the material for seed production in clonal seed orchards. Seed orchards are plantations created for production of genetically improved seeds to create commercial forest crops. The genetic quality of the seeds depends on the genetic superiority of the plus trees, their relationships, their combination ability, and the rate of pollen contamination, among other factors.

Variation in fertility and flowering phenology are generally known to affect the genetic composition of seed orchard crops (GöMÖRY et al., 2003). Thus, to improve tree quality it is important to investigate the variation in fertility and flowering phenology in seed orchards and to make predictions about the genetic composition of the seed crop. Significant genetic variation in flowering time has previously been reported for different Prunus spp. (Couranjou, 1995; DiCEnTA et al., 1993; Hansche, 1990; HANSCHE et al., 1966), Malus sylvestris (L.) Mill. (LABuschagne et al., 2002), and Pistacea vera L. (CHAO and PARFITT, 2003), among others.

Large differences in fertility among clones have been reported in conifer clonal seed orchards (e.g. MERLO and FERNÁNDEZ-LÓPEZ (2004)). Generally, only a fraction of the individuals in a population contribute to much of the 